\title{
RELATO DE UMA EXPERIÊNCIA: A CRIAÇÃO DO FUNDO DOCUMENTAL NEUSA CARSON
}

\author{
REPORT OF AN EXPERIMENT: THE CREATION OF NEUSA \\ CARSON DOCUMENTAL FUND
}

\author{
Simone de Mello de Oliveira (UFSM) ${ }^{1}$
}

\begin{abstract}
Resumo: Este artigo apresenta como está acontecendo o processo de constituição do Fundo Documental Neusa Carson, o qual teve sua origem no projeto de pesquisa "A linguística no Sul: estudo das ideias e organização da memória", coordenado por Amanda Scherer. Trazemos elementos desde sua fase embrionária até nossos dias. O Fundo encontra-se atualmente em fase final de tratamento de organização e, em breve, será disponibilizado para pesquisa.

Palavras-chave: fundo documental; processo de constituição; Neusa Carson.

Abstract: This article presents the constitution process of the Neusa Carson Documental Fund, which had its origin in the research project "The language in the South: the study of ideas and memory organization", coordinated by Amanda Scherer. We bring elements from its embryonic stage to the present day. The Fund is currently in the final stages of treatment organization and will soon be available for research.

Keywords: documental fund; constitution process; Neusa Carson.
\end{abstract}

\section{Introdução}

Apresentaremos, neste texto, um relato da experiência de criação do Fundo Documental Neusa Carson, doravante FDNC, em três momentos distintos: o primeiro deles, "a Linguística no Sul", que historiciza a criação do projeto que dá início aos estudos sobre a memória e a história disciplinar contemporânea de pesquisadores do sul do Brasil, momento anterior a nossa entrada no projeto; o segundo, "desenvolvimentos atuais", que registra os acontecimentos realizados e vivenciados por nós enquanto participantes da coordenação executiva do FDNC; e o terceiro momento, "projeções futuras", que projeta brevemente as atividades dos anos de 2013 e 2014.

\section{A Linguística no Sul}

Em 2001, foi criado o Laboratório Corpus, por meio do projeto "Criação do Laboratório Corpus: formação de pesquisadores em Ciências da

1 Bolsista de Pós-Doutorado PNPD/CAPES 2011-2013. Pesquisadora do Laboratório Corpus (UFSM). E-mail: simone.mo@gmail.com 
Linguagem", sob o registro no 9537, no Gabinete de Projetos do Centro de Artes e Letras da Universidade Federal de Santa Maria.

No ano seguinte, em 2002, Scherer, atual coordenadora geral do Laboratório Corpus, propôs o projeto interdisciplinar Linguistica e História Literária no Sul: estudo das ideias e organização da memória (registro $\mathrm{n}^{\circ} 12344$ GAP/CAL - UFSM). Como resultado dessa pesquisa, em 2005, publicou o artigo Linguística no Sul: estudo das ideias e organização da memória, no livro Sentido e Memória, organizado por Guimarães e Brum de Paula. Já em 2006, a pesquisadora registrou, no Gabinete de Projetos/CAL - UFSM (registro $\mathrm{n}^{\circ}$ 019213), o desmembramento do projeto inicial, também sob sua coordenação, intitulado Linguística no Sul: estudo das ideias e organização da memória dos anos 80 a 2000. Esses projetos são o marco inicial dos trabalhos com a memória e a História das Ideias Linguísticas de pesquisadores do Sul do Brasil.

Nesse projeto de 2006, uma bolsista PIBIC-CNPq de iniciação científica (IC) dedica-se a estudar as ementas dos cursos de Letras da UFSM, de onde o nome Neusa Carson surge com força suficiente para redimensionar o estudo e a orientação do projeto. Neusa Carson passa a ser o objeto principal do estudo de IC de Juciele Dias, que publica dois artigos relacionados à temática, sendo um na revista Ideias e o outro na Coleção Fragmentum (DIAS, 2007).

Tempos depois, já como aluna de doutorado, Juciele Dias intermediou a doação do espólio da pesquisadora Neusa Carson, pela família, à UFSM, representada na pessoa da Prof. ${ }^{a}$ Amanda. Scherer. A doação desse material foi realizada no dia 20 de agosto de 2011, por Hugo Carson, filho de Neusa Carson, representante da família (Fotografia 01). Com a doação, propiciou-se a criação do Fundo Documental Neusa Carson. 


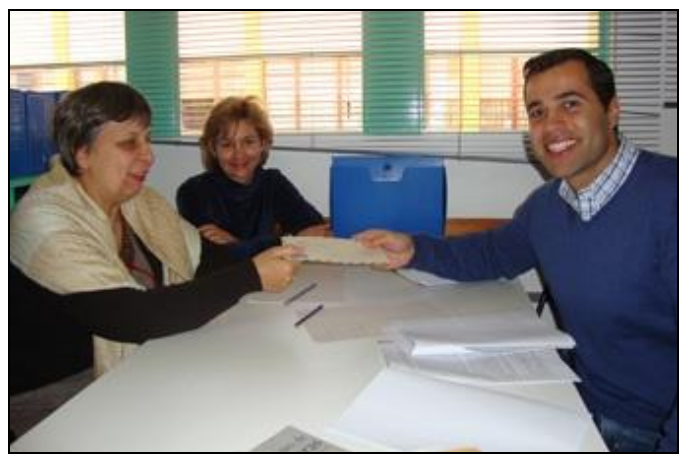

Fotografia 01 - Da esquerda para a direita: Prof. ${ }^{a}$ Dr. ${ }^{a}$ Amanda Eloina Scherer, Prof. ${ }^{a}$ Ms. Leila Marachin e Hugo Carson. Fonte: Arquivo fotográfico do Laboratório Corpus.

\section{Desenvolvimentos atuais}

Em 2011, o projeto Linguística no Sul: estudo das ideias e organização da memória foi contemplado pela Capes no edital Programa Nacional de PósDoutoramento, com duas bolsas de pós-doutoramento, que foram preenchidas respectivamente pelas professoras recém-doutoras, Zélia Maria Viana Paim (UFSM) e Simone de Mello de Oliveira (UNICAMP). Enquanto pesquisas relacionadas às revistas acadêmicas ficaram com a primeira, as atividades relativas à Criação do Fundo Documental Neusa Carson ficaram sob a responsabilidade da Prof. ${ }^{a}$ Dr. ${ }^{a}$ Simone de Mello de Oliveira.

A primeira atividade relativa ao fundo foi a criação e o registro do Projeto do Fundo Documental Neusa Carson junto ao Gabinete de Projetos do Centro de Artes e Letras, que recebeu o número 031245. De posse desse projeto, participamos do edital interno de seleção de projetos de extensão FIEX, do ano de 2012, na modalidade Programa de Extensão, com um conjunto de projetos do Laboratório Corpus, entre eles, o Fundo Documental Neusa Carson. Fomos contemplados com uma bolsa que ficou sob nossa responsabilidade, para a realização do trabalho arquivístico sobre o FDNC, em linhas gerais, higienização, organização, arranjo e descrição dos documentos e objetos.

Para esse processo, estabelecemos uma parceria com o curso de Arquivologia da UFSM, na pessoa da Prof. ${ }^{a}$ Ms. Rosani Pivetta, que orientou a bolsista Carla Saldanha, acadêmica do curso de Arquivologia, no desenvolvimento do trabalho. Dessa forma, demos origem ao que chamamos de Polo Arquivologia. 
Fixou-se, como local provisório para o desenvolvimento desse trabalho e guarda do Fundo, a sala 3319B do Centro de Educação, da UFSM, sala essa de trabalho da Prof.a Amanda Scherer.

Em 2013, o projeto Linguistica no Sul: estudo das ideias e organização da memória - Parte II foi registrado sob o n ${ }^{\circ}$ 033989, no Gabinete de Projetos do Centro de Artes e Letras da UFSM. Nesse novo projeto, passou a ser prevista, também, a criação de Fundos Documentais de outros professores e a criação de uma política de fundos documentais para a UFSM.

Com o início dos trabalhos de arranjo e de descrição da documentação de Neusa Carson, ficou evidente a quantidade de documentos em língua inglesa produzidos e recebidos pela referida professora ao longo de sua vida. Neusa realizou sua formação de pós-graduação (mestrado, doutorado e pós-doutorado) nos Estados Unidos. Em função disso, para realizar as traduções e as descrições desses documentos escritos em inglês, criamos o Polo Inglês, composto pelas acadêmicas Bruna Cielo e Juliana Ribeiro, ambas acadêmicas do curso de Letras da UFSM, e coordenado pela técnicaadministrativa Daniela do Canto $^{2}$, tradutora e intérprete do Serviço de Apoio Internacional da UFSM.

Um terceiro polo foi também criado, o Polo Pesquisa. Nesse, trabalham os pesquisadores dedicados ao FDNC, as Prof.as Amanda Eloina Scherer, Verli Petri da Silveira, Simone de Mello de Oliveira, Zélia Maria Viana Paim e Taís da Silva Martins. Como produção científica proveniente do Polo Pesquisa, temos o artigo científico aceito para publicação na revista Gragoatá n. 34 (periódico A1 Qualis CAPES), intitulado Arquivo, memória e acontecimento em uma politica de Fundos Documentais, bem como outras apresentações de trabalhos em eventos da área, a saber:

- OLIVEIRA, S. de M de. A (re)documentalização na era da internet e a constituição do Fundo Documental Neusa Carson. (X CELSUL, 2012).

- OLIVEIRA, S. de M. de. Arquivo e (re)documenta(riza)şão: a criação do Centro de Documentação e Memória. (ENLACE entre LABORATÓRIOS).

- CABRERA, Bruna C. A criação do fundo documental Neusa Carson como forma de preservação da memória dos estudos linguísticos na UFSM. (ENLACE entre LABORATÓRIOS) (IC/FIEX).

Da mesma forma, citamos a organização do evento XIX Seminário Corpus, em 2012, com as atividades destacadas abaixo:

- Conferência 1: Le corpus Benveniste pour la recherche, Irène Fenoglio (CNRS, ITEM/ENS - FR);

${ }^{2}$ Licenciada em Letras Hab. Português/Inglês pela UFSM, com especialização pela UGF em Ensino de Língua Inglesa e Uso de Novas Tecnologias. 
-Conferência 2: Présentation sur la génétique du texte avec application aux manuscrits de linguistes et en particulier Benveniste, Irène Fenoglio (CNRS, ITEM/ENS - FR);

-Conversa com Pesquisador, com Irène Fenoglio (CNRS, ITEM/ENS - FR); e

- Mini-curso: Acervos Literários: entre a memória e a história, com Maria da Glória Bordini (UFRGS).

Em 11 de abril de 2013, apresentamos o FDNC ao reitor da UFSM, Prof. Felipe Martins Müller, ocasião em que também apresentamos a planta do que futuramente poderá ser o prédio do Centro de Documentação e Memória. Essa reunião se configurou como uma solicitação formal de sede própria para o FDNC e os demais fundos sob custódia do Laboratório Corpus. Estavam presentes nessa reunião os professores Pedro Brum Santos (diretor do Centro de Arte e Letras), Amanda Scherer (coordenadora geral do Laboratório Corpus), Verli Petri (coordenadora acadêmico-científica do Laboratório Corpus), Simone de Mello de Oliveira (coordenadora executiva do FDNC), Zélia Maria Viana Paim (PNPD/CAPES), Taís da Silva Martins (DOCFIX FAPERGS/CAPES), Enéias Tavares (DLCL), a técnico-administrativa Daniela do Canto (coordenadora do Polo Inglês) e a arquivista Carla Saldanha.

Em 12 de abril de 2013, promovemos uma reunião da equipe do FDNC com Hugo Carson, filho de Neusa Carson e doador do material que compõe o fundo (Fotografia 02). Na ocasião, apresentamos os trabalhos desenvolvidos até aquele momento, tanto de organização e arranjo arquivístico quanto de produção científica. Também tratamos dos planos para o futuro próximo. Nessa data, formalizamos a doação através da assinatura de um termo de doação (Fotografia 03) elaborado pela bacharel em direito e doutoranda em Letras - Estudos Linguísticos, Carolina Lisowski. 


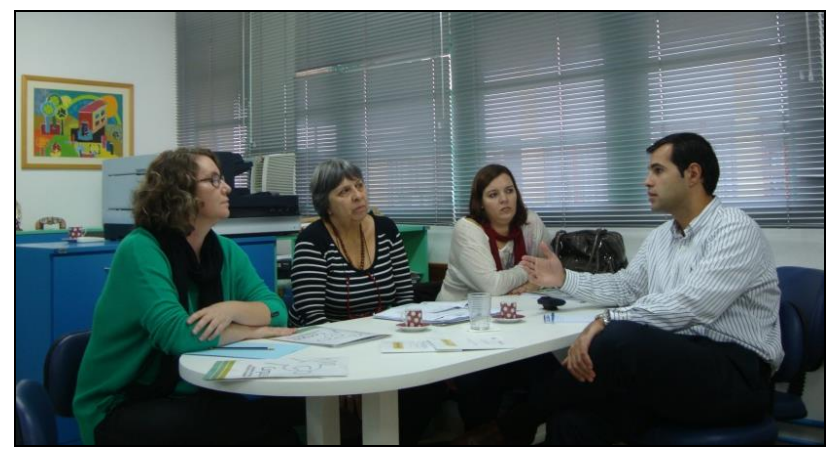

Fotografia 02 - Reunião de apresentação do andamento dos trabalhos do FDNC e assinatura do termo oficial de doação. Da esquerda para a direita, Professoras Simone de Mello de Oliveira e

Amanda Eloina Scherer, a técnica-administrativa Daniela do Canto e Hugo Carson. Fonte: Arquivo fotográfico do Laboratório Corpus.

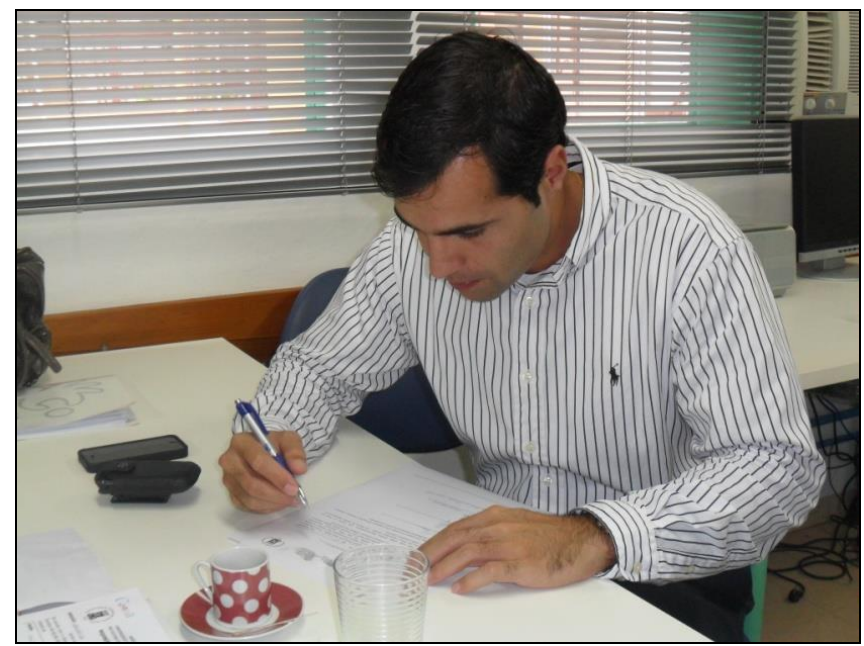

Fotografia 03 - Hugo Carson no momento da assinatura do termo de doação. Fonte: Arquivo fotográfico do Laboratório Corpus.

\section{Projeções futuras}

Apresentaremos, na sequência, a previsão das atividades que dizem respeito ao Fundo Documental Neusa Carson para os anos de 2013 e 2014. A primeira delas é a publicação do presente número da Coleção Fragmentum, , com a temática "Fundo Documental Neusa Carson", organizado por Simone de Mello de Oliveira (UFSM) e Nádia Régia Maffi Neckel (UNISUL). Já para o 
mês de outubro, está previsto o XX Seminário Corpus e I Encontro do Grupo de Pesquisa do CNPq Linguagem, Sentido e Memória, que terá o conceito de arquivo como temática geral.

Também está sendo organizada uma atividade de cunho extencionista e de divulgação cientifica da área de Letras, a saber, a Exposição Neusa Carson: Lngua e Memória, que acontecerá de 21 de outubro a 01 de novembro de 2013, na Sala Cláudio Carriconde/CAL - UFSM. Esse evento tem a coordenação geral de Amanda Eloina Scherer; coordenação executiva de Simone de Mello de Oliveira; equipe de curadoria composta pelos professores Elcio Gimenez Rossini (UFSM), Lucília Maria Sousa Romão (USP-Ribeirão Preto), Marília de Araujo Barcellos (UFSM), Nara Cristina Santos (UFSM), Nádia Régia Maffi Neckel (UNISUL) e Nadja de Carvalho Lamas (UNIVILLE); assessoria documental da arquivista Carla Saldanha (UFSM); revisão dos textos de Larissa Montagner Cervo (UFSM); membros da comissão organizadora Taís da Silva Martins (DOCFIX/ FAPERGS/ CAPES/ UFSM), Verli Petri da Silveira (UFSM), Zélia Maria Viana Paim (PNPD/CAPES/UFSM); e membros da comissão de apoio a técnica-administrativa Daniela do Canto (SAI/UFSM) e o mestrando Carlos Alberto Donaduzzi (PPGART/UFSM).

Duas reuniões gerais das comissões de organização e curadoria da exposição já foram realizadas até o presente momento, respectivamente em fevereiro e julho de 2013. Nelas, foram traçadas as linhas gerais da exposição, que está sendo pensada em seu desenho expográfico por Elcio Rossini. A exposição contará o percurso e a atuação de Neusa Carson como pesquisadora da área de Letras nos anos 70 e 80, bem como o pioneirismo em sua formação, haja vista o que prevê o projeto Linguística no Sul: estudos das ideias e organização da memória, que tem como um de seus objetivos propor uma reflexão sobre a memória e a história disciplinar contemporânea de pesquisadores do Sul do Brasil, a fim de desencadear a institucionalização de uma política de Fundo Documental para a UFSM.

Para 2014, está prevista a digitalização completa dos documentos do FDNC, que já está em fase inicial de andamento, bem como a publicação de um livro sobre a temática arquivo, proveniente do evento sobre a mesma temática, que acontecerá em outubro de 2013, sob a organização das Professoras Amanda Eloina Scherer e Verli Petri.

\section{Considerações finais}

O projeto 'guarda-chuva' Linguística no Sul desenvolve-se desde 2002 em suas diversas fases até o momento atual, sob a coordenação de Amanda Eloina Scherer, contando com vários colaboradores desde então e desenvolvendo uma pesquisa séria através de uma política de recuperação da 
memória e da história disciplinar contemporânea, a partir da criação de Fundos Documentais.

Afora o Fundo Documental Neusa Carson, que foi o primeiro a receber recursos da FAPERGS, do CNPq e da CAPES, além do Programa de Extensão FIEX - UFSM, já foram criados o Fundo Documental Aldema Menine Mckinney, o Fundo Documental Maria Luiza Ritzel Remédios e o Acervo Michael Phillips. Também, está prevista a criação do Fundo Felipe D’Oliveira. Por meio dos documentos pertencentes a esse (s) fundo (s), podemos recontar cientificamente fragmentos de histórias, memórias e pesquisas que foram primordiais para a constituição dos estudos das ciências da linguagem.

O percurso descrito neste relato trata do trabalho com o Fundo Documental Neusa Carson, associando às atividades de organização, geração de pesquisas e divulgação, aspectos considerados primordiais para o desenvolvimento do trabalho com fundos e a criação de uma política de Fundos Documentais para a UFSM.

\section{REFERÊNCIAS}

DIAS, Juciele Pereira; Rosa, Marluza Terezinha da. Os passos de uma pesquisadora trilhando caminhos da Linguística no sul. In: SCHERER, Amanda; PETRI, Verli; DIAS, Cristiane. Memória em terceira pessoa. Santa Maria, RS: PPGL Editores, 2013 (no prelo).

DIAS, Juciele Pereira. Uma leitura sobre a hipótese crioulística do português do Brasil. Fragmentum, n. 13, Santa Maria/RS, Laboratório Corpus, 2007. PETRI, Verli. Por um acesso fecundo ao arquivo. Letras (UFSM), Santa Maria/RS, v. 1, n. 21, p. 121-125, 2002.

SILVA, Rosani Beatriz Pivetta da; CASTANHO, Denise Molon; GARCIA, Olga Maria Correa. Arranjo e descrição de documentos arquivísticos. Santa Maria, RS: UFSM, 2006.

SCHERER, A. E. Lingüística no sul: estudo das idéias e organização da memória. In: GUIMARÃES, Eduardo; PAULA, Mirian Rose Brum de. (Org.). Sentido e memória. Campinas, SP: Pontes, 2005.

SCHERER, Amanda; PETRI, Verli; MELLO, Simone; PAIM, Zélia. Arquivo, memória e acontecimento em uma política de Fundos Documentais. In: Gragoatá. Rio de Janeiro: Editora da UFF, 2013 (no prelo). 